\title{
Obtaining Natural Biopolymers Films of Quercus robur L and Roasted Seeds of Vitis vinifera Grapes
}

\author{
MIHAELA GABRIELA DUMITRU*, ANCA GANESCU \\ University of Craiova, Faculty of Science, Department of Chemistry, 107i, Calea Bucuresti 200585, Craiova, România
}

The objective of this study was to analyse the role of package obtained from a natural biopolymer of Quercurs robur $L$ incorporating natural antioxidant compounds found in roasted seeds of grapes to lipid oxidation of butter during storage. Also were determined the properties of film: solubility in water, determination of antioxidant activity and water sorption activity. Were formed two sets of butter samples packed in paper respectively in a biopolymer mixed with antioxidant. Samples were stored at a temperature of $+6^{\circ} \mathrm{C}$ for a period of fourty days. Frequently was determined the peroxide index. The values of peroxide index show the role of package obtained from starch and polyphenolics extract of roasted seeds of Vitis vinifera grapes on lipid found in butter.

Keywords: starch, Quercus robur, Vitis vinifera, butter

Edible films or coatings are generally defined as thin layers of material, which can be eaten by consumer as part of food [1]. Films or coatings can be used to cover food surface or used as pouches or wraps. These can provide food with different functionalities such as a barrier that improves its mechanic resistance, also they hinders the loss of solutes and volatiles or flavors, and controls the transfer of moisture, oil and gases such as oxygen and carbon dioxide. It is also important that films, improves appearance of the food product [1-3].

An aspect providing great versatility and interest in edible coatings nowadays is incorporating active natural compounds from plants that could act as antioxidant, antimicrobial and/or antibrowning agents as well as crosslinking agents. The interactions of active natural compounds with the polymeric matrix may not only affect their release into food, but also alter some functionalities or physical and chemical properties of film, such as solubility, light and gas barrier properties [3-5], as well as elasticity, resistance and appearance. Besides, some studies have shown that antioxidant power (reducing ability and free radical-scavenging capacity) as well as light barrier properties of biodegradable and edible films can be increased by adding antioxidants.

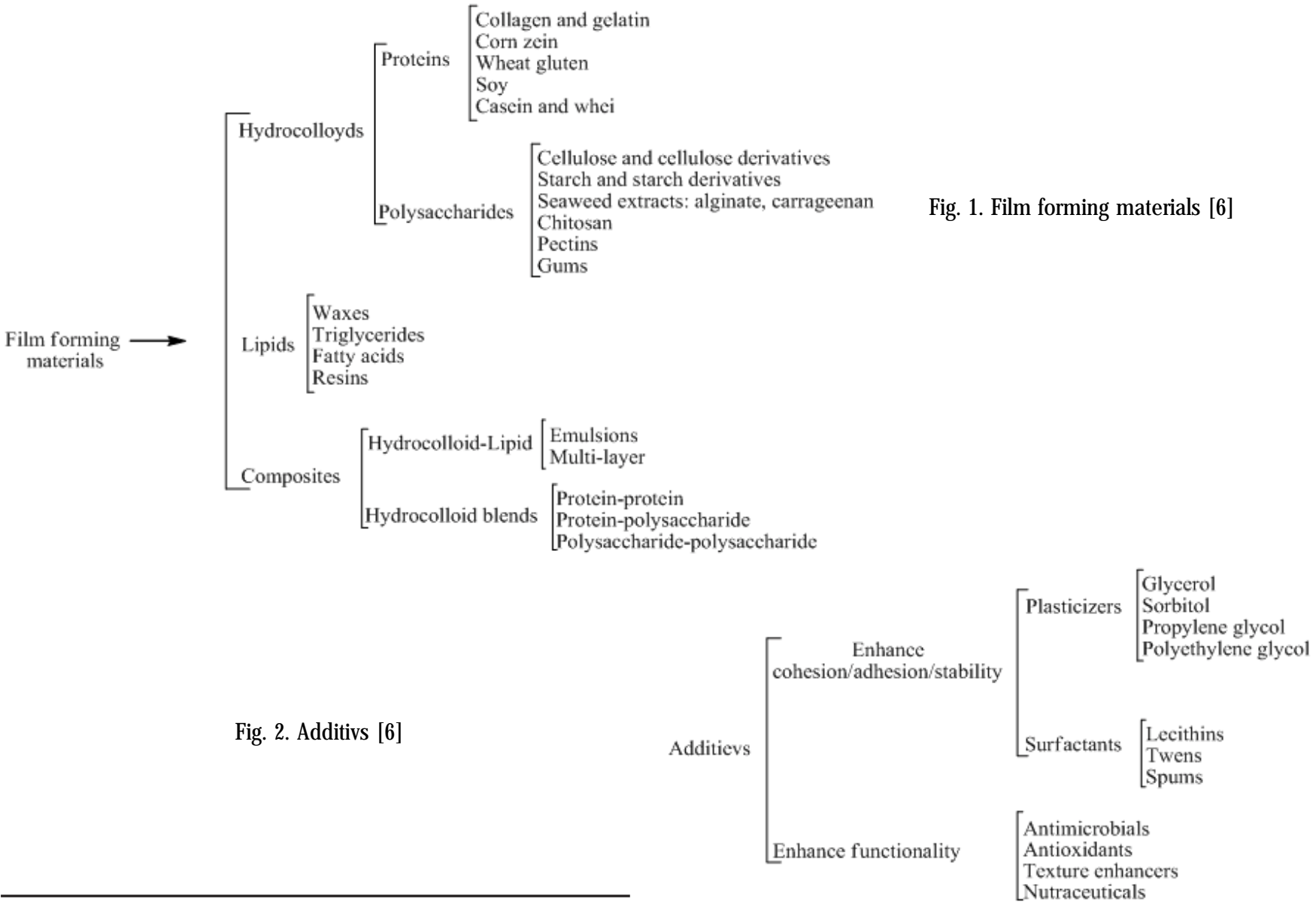




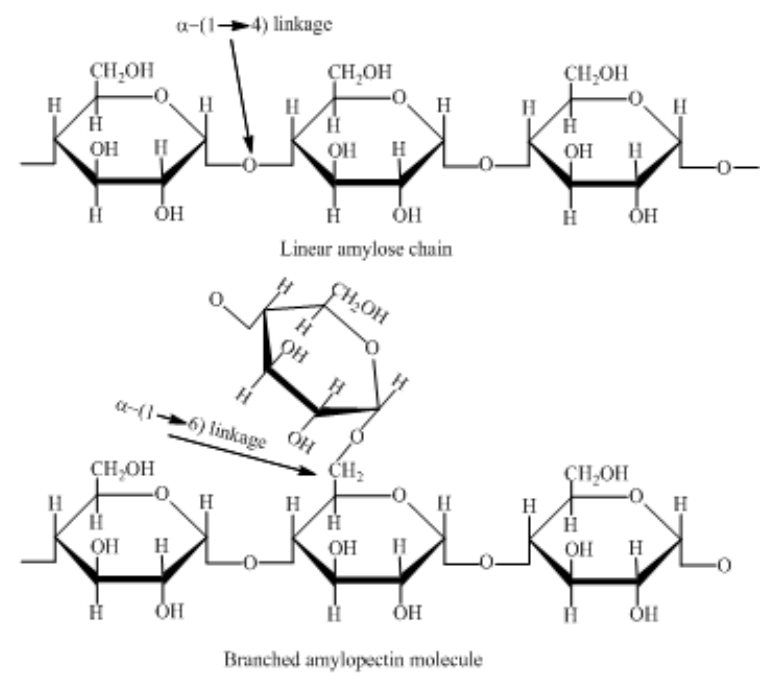

Fig. 3. Starch

Native starch, which occurs in a granular form, is one of the main carbohydrate resources found in cereal and plants. The main components of starch are linear amylose and highly branched amylopectin composed of glucose units via $\alpha-1,4$ bonds. Amylopectin contains also $2-4 \%$ branching points formed by $\alpha-1,6$ bonds on the main backbone and other branches, (fig. 3) [7].

The application of starch-based films in food packaging is promising because of their environmental appeal, low cost, flexibility and transparency $[8,9]$. Edible films made from starch are tasteless, odourless and transparent, thus prevent a change of taste, flavour and appearance of food products [10]. Tensile strength and flexibility of starch films are determined by macromolecular chain mobility in the amorphous phase, amylose: amylopectin ratio, plasticizer and water content. Main advantages of starch films are excellent barrier properties to $\mathrm{O}_{2}$ and $\mathrm{CO}_{2}$ [11].

The search for new renewable resources for the production of edible and biodegradable materials is increasing in the last years. Non-conventional sources of carbohydrates are an interesting alternative. Starch is the main component of acorns, amounting to over $40-55 \%$ of the kernel [12-14].

The aim of this article is to obtain films containing polysaccharide of Quercus robur $L$ incorporating active natural antioxidant compounds from roasted seeds of Vitis vinifera grapes to increase oxidative stability during the storage of butter.

Butter is considered one of the most popular concentrated milk products. Its nutritive value is high and is based on fat content. Digestibility of butter is $97 \%$ for fat and $94 \%$ for dry plasma and represents an important source of $E$ vitamin. During storage or food processing, lipid autoxidation is the main reaction for organoleptic (color, flavor, change of texture) and nutritional (loss of essential fatty acids, nutritional losses) deterioration. Lipid oxidation includes fatty acid oxidation and generates compounds that affect food quality, due to changes in color, flavor, texture and even nutrition and food safety [15].

\section{Experimental part}

Materials and methods

Acorns (Quercus robur $\mathrm{L}$ ) were collected in october 2016 from the surroundings of the Faculty of Science, Department of Chemistry, University of Craiova, Romania. The acorns were inspected in order to separate fruits with defects or disease, and stored at room temperature.

Vitis vinifera seeds were purchased from the Research Station of the University of Craiova,Romania having the following characteristics: the appearance: the dry surface without any trace of mold; the color: brown or dark red, various shades, characteristic for the variety of provenance; smell: is specific from the seed of Vitis vinifera, but it is not allowed the smell of mould; seeds altered: less than $5 \%$; impurities (pieces of the bunch, skin): below 3\%; the moisture: 35-40\%; density: 1.1-1.3 $\mathrm{g} / \mathrm{cm}^{3}$; higroscopicity: 7-15 mL/100 g [16, 17]. $85 \%$.

Butter purchased commercially with a fat content of

Package made from sanitary approved white paper, having a weight of $35-50 \mathrm{~g} / \mathrm{m}^{2}$, was used in direct contact with food.

\section{Extraction of total polyphenols contained in roasted seeds} of Vitis vinifera grapes

The seed roasting was done in a Rombat type roaster for $15 \mathrm{~min}$ at $220^{\circ} \mathrm{C}$ and grinding was made in a Viacenzatype machine 200 adjusted so that to obtain a $1-1.25 \mathrm{~mm}$ particle size $[17,18]$.

The extraction of polyphenols from grapes of Vitis vinifera roasted seeds was performed in a spherical reactor with a capacity of $1 \mathrm{~L}$ in which, to the obtained powder was added $100 \mathrm{~g}$ of Vitis vinifera seeds and $300 \mathrm{~mL}$ of distilled water. The mixture was heated at $80^{\circ} \mathrm{C}$ for $2 \mathrm{~h}$. The obtained extract was filtered through filter paper and stored in a refrigerator [19].

\section{Determination of total polyphenol contentin roasted seeds} of Vitis vinifera grapes

The total polyphenol content was measured using the Folin Ciocalteu colorimetric method. To $800 \mu \mathrm{L}$ of deionised water, $50 \mu \mathrm{L}$ of Folin Ciocalteu reagent and a volume of sample ranging from 10 to $50 \mu \mathrm{L}$ were added and accurately mixed. After $1 \mathrm{~min}, 100 \mathrm{~mL}$ of $20 \%$ sodium carbonate solution was added and mixed. Deionised water was then added up to a volume of $1 \mathrm{~mL}$. The solution was carefully mixed and total phenol content was spectrophotometrically estimated at $765 \mathrm{~nm}$ after $2 \mathrm{~h}$ incubation. Quantification was based on the standard curve generated with gallic acid [17].

\section{Extraction of starch from Quercus robur $\mathrm{L}$ acorns}

The selected acorns were peeled and cut into small pieces. Representative samples of $1 \mathrm{~kg}$ were ground in a blender with $1.5 \mathrm{~L}$ of water $\left(t=90^{\circ} \mathrm{C}\right)$ containing a small amount of potassium disulfite ( $2.5 \mathrm{~g}$ potassium disulfite /L $\mathrm{H}_{2} \mathrm{O}$ ), to avoid acorn browning.

${ }^{2}$ The slurrywas filtered through sieves and then separated in residue and filtrate. Settled solids were separated from the supernatant and washed with distilled water until a clear wash was obtained and the starch was free of colour; the starch was then dried in a ventilated oven at $45^{\circ} \mathrm{C}$, Fig. 4.

\section{Preparation of films}

In a $200 \mathrm{~mL}$ reactor were introduced $3 \mathrm{~g}$ of starch pow der, $100 \mathrm{~g}$ of the aqueous extract obtained from the roasted seeds of Vitis vinifera grapes and $1 \mathrm{~g}$ of glycerol in order to obtain a flexible and elastic film. The mixture was heated in a water bath at $60^{\circ} \mathrm{C}$ for $60 \mathrm{~min}$ and then degassed under vacuum.

\section{Coating the film}

There are several processes of forming biopolymers films such as pouring, spraying, extrusion and thermoforming. The most common method used in the laboratory is pouring. In this case, the film-forming solution, was poured on a non-sticking plate (glass) and left in atmosphere for 


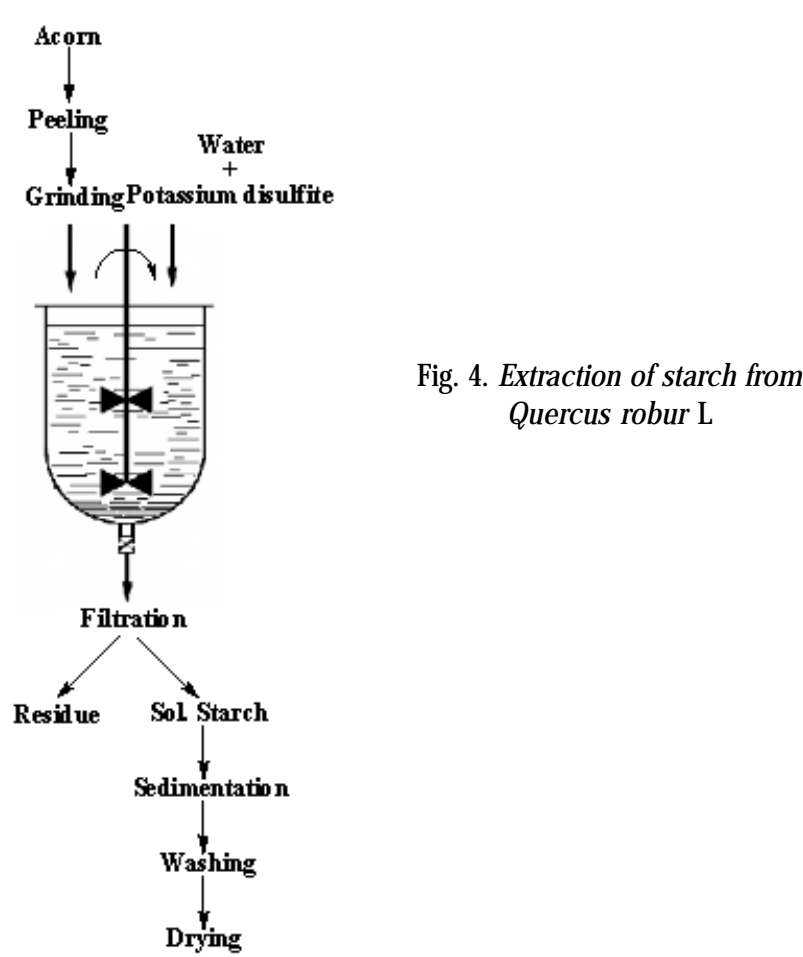

$24 \mathrm{~h}$ to evaporate the solvent and form the film [17] and dried at $40^{\circ} \mathrm{C}$ for $16 \mathrm{~h}$ in an oven with circulating air. The dried film samples were conditioned at $25^{\circ} \mathrm{C}$.

\section{Determination of the Film Properties}

Determination of Solubility in Water of the Polymer Film

The solubility of the polymer film represents the dissolved dry matter content after a $24 \mathrm{~h}$ immersion in water. The initial content of dry matter of the film was determined using a MX-50 thermogravimetric balance. Discs ( $2 \mathrm{~cm}$ diameter) were cut, weighed $\left(\mathrm{M}_{\mathrm{i}}\right)$, and placed in a volume of $50 \mathrm{~mL}$ distilled water. After $24 \mathrm{~h}$ of immersion the samples were removed and dried in a Memmert oven at $105^{\circ} \mathrm{C}$ to constant weight $\left(\mathrm{M}_{\mathrm{f}}\right)$ to determine the weight of dried material which has not been solubilized in water. The solubility of the film was determined by the formula $[17,20]$ :

$$
\text { Water solubility } \%=\left(M_{i}-M_{f}\right) / M_{i} \times 100
$$

where $M_{i}$ - the initial mass of the film; $M_{f}$ - final mass of film.

Determination of antioxidant activity by DPPH method

One $\mathrm{mL}$ of the extract in methanol was added to $4 \mathrm{~mL}$ of $0.1 \mathrm{mmol} / \mathrm{L}$ methanolic solution of DPPH. A blank probe was obtained by mixing $4 \mathrm{~mL}$ of $0.1 \mathrm{mmol} / \mathrm{L}$ methanolic solution of DPPH and $200 \mu \mathrm{L}$ of deionized distilled water. After 30 min of incubation in the dark at room temperature, the absorbance was read at $517 \mathrm{~nm}$ against the prepared blank. Inhibition of free radicals by DPPH in percent (I \%) was calculated using this formula [17, 21]:

$$
1 \%=\left(A_{\text {blanc }}-A_{\text {sample }}\right) / A_{\text {blanc }} 100
$$

where $A_{\text {ban }}$ is the absorbance of the control reaction containingall reagents except the test compound and $A_{\text {sample }}$ is the absorbance of the test compound.

\section{Determination of the Water Sorption Isotherm of the Polymer Film}

The graphical representation of the balance between hard moisture and water activity is called water sorption isotherm. Calculation of the equilibrium moisture content $\mathrm{m}$ of the film samples with moisture zero was carried out by placing them in desiccators containing saturated salt solutions. At a constant temperature $\left(25^{\circ} \mathrm{C}\right)$ saturated salt solutions used have a water activity between 0.1 and 0.9 . The data were graphically processed using a special program for obtaining water sorption isotherms (AWRPLOT), adapted equation GAB (GuggenheimAnderson-duBoer) [17], (fig. 5):

$$
m=\frac{m_{0} \cdot K_{b} \cdot C \cdot a_{w}}{\left(1-K_{b} \cdot a_{w}\right)\left(1-K_{b} \cdot a_{w}+K_{b} \cdot C \cdot a_{w}\right)}
$$

where:

$\mathrm{m}$ - humidity balance, $\mathrm{g}$ water/g film;

$\mathrm{m}_{0}$ - optimal humidity (monolayer), g water $/ \mathrm{g}$ film;

$a_{w}$ - water activity;

$\mathrm{K}_{b}^{\mathrm{w}}$ - constant correction;

$C^{b}$ - constant Guggenheim.

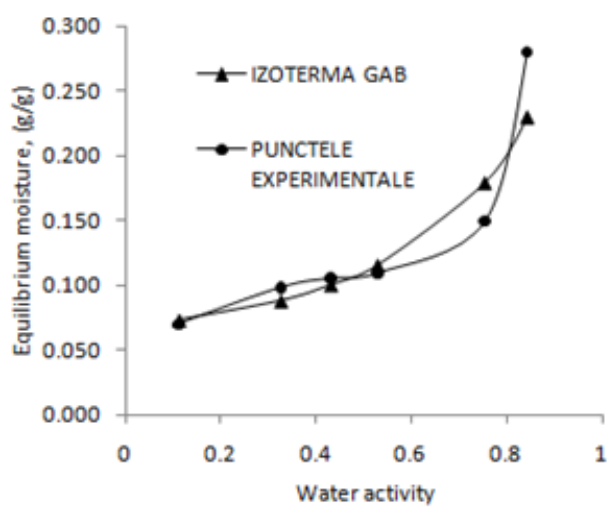

Fig. 5. Determination of the Water Sorption Isotherm

Were made 2 sets of samples:

-butter packed in white paper;

-butter packed in polymer film.

The samples were stored at a temperature of $+6^{\circ} \mathrm{C}$ for a period of forty days and frequently were determined peroxides indexes at each ten days.

\section{Determination of peroxide index by Hara-Totani method}

Peroxide index of butter samples was determined at the beginning and after determining oxidative stability by Hara-Totani [22-24]. In a $250 \mathrm{~mL}$ conical bottle was weighed on analytical balance a fixed quantity of butter (20 mg) and were dissolved in $10 \mathrm{~mL}$ chloroform. Add 15 $\mathrm{mL}$ glacial acetic acid and mix. After replacing air with nitrogen or $\mathrm{CO}_{2}$, add $0.3 \mathrm{~mL}$ saturated $\mathrm{KI}$ solution and shake for 1 minute, followed by cooling in ice water bath in the dark. Add $100 \mathrm{~mL}$ cold distilled water and shake and then titrated potentiometrically with sodium thiosulfate solution $0.001 \mathrm{~N}$ keeping the bottle in ice bath. During titration, there is a change in potential that in the equivalence moment shows a sudden drop. Parallel running a blank solution without butter where volume $0.001 \mathrm{~N}$ sodium thiosulphate used in titration until the equivalence point should not exceed $0.15 \mathrm{~mL}$. If this amount is exceeded then another will prepare a saturated solution of $\mathrm{KI}$. Index value is calculated in milliequivalents peroxide oxygen $/ \mathrm{kg}$ butter using formula:

$$
I P=\frac{\left(V-V_{m}\right) \cdot F \cdot N \cdot 1000}{m} m E q O_{2} / K g \text { butter }
$$

where:

$\mathrm{V}$ - number $\mathrm{ml} 0.001 \mathrm{~N}$ sodium thiosulphate solution used for titration of sample to be analyzed;

$\mathrm{V}_{\mathrm{m}}$ - number $\mathrm{ml} 0.001 \mathrm{~N}$ sodium thiosulphate solution used in blank titration; 
$\mathrm{m}$ - mass of butter sample $(\mathrm{g})$;

$\mathrm{F}$ - factor solution $0.001 \mathrm{~N}$ sodium thiosulphate;

$\mathrm{N}$ - normality of $0.001 \mathrm{~N}$ sodium thiosulphate.

\section{Results and discussions}

In food packaging technique, required materials are light wrappers adapted to specific demands of wrapped products and made, if possible, from environmentally convenientmaterial (for example, biopolymers). Atpresent, active packagings (films, foils, coatings) are being increasingly used and these directly influence quality and storage life of products by limiting or regulating permeability of gases $\left(\mathrm{O}_{2}, \mathrm{CO}_{2}\right)$ and water vapour, and regulate atmosphere inside the wrapping [25-28].

Due to its availability, low cost and ability to impart a broad range of functional properties to different kinds of products, starch is used in several industrial applications [29].

A very important source of starch is the acorns of Quercus robur $\mathrm{L}$ that beside Fagus sylvatica are cultivated on a large area in Romania (130.000 Ha) [30].

A number of recent studies have focused on extending the functional properties of biodegradable films by adding different natural compounds to yield a biodegradable totally bioactive packaging material [31-34]. Active packaging films with antioxidant properties, developed by incorporating active functional ingredients into packaging systems, can offer protection against chemical and biological contamination [31, 35, 36], and can delay oxidative changes in packaged products containing fatty components [37]. Oxidation is one of the most common mechanisms of degradation in foodstuffs and can limit the shelf life of food [37, 38].

Therefore, a need exists in the food industry to develop polymer packaging which can deliver natural antioxidants in a controlled manner throughout the product shelf life $[31,39,40]$.

In the present study, a Vitis vinifera seed polyphenol extract was used as an antioxidant agent. The fact that the grapes seeds, through their content in polyphenols (gallic acid, monomers flavan-3-ol (catechin, epicatechin, galocatechin, epicatechin 3-0-gallate); dimers, trimers and polymers procyanidins), develop an antioxidant activity 20 times higher than vitamin $\mathrm{C}$ and 50 times stronger than vitamin $\mathrm{E}[41,42]$ have helped to protect the butter during storage. This antioxidant effect is highlighted by the values obtained for butter packed in starch film obtained from acorns of Quercus robur $L$ and of seeds of grapes of Vitis vinifera extract. We consider that an important role is played by the pyrogallol formation from hydrolysable tannins which increase the antioxidant effect of extract.

The resultant for starch extraction were $11.8 \%$ The film produced from starch were homogene, smooth and translucent.

By using the polyphenol extract of grapes seeds whose concentration in polyphenols was 610 in $\mathrm{mg} \mathrm{GAE} / 100 \mathrm{~g}$ grapes seed powder of Vitis vinifera, it was obtained a film whose antioxidant activity was determined by the DPPH method of $78 \%$. High antioxidant activity of the film helps to lower the rate constant for the oxidation reaction thus protecting the active ingredients in food from oxygen.

The film solubility in water can also provide an insight about the behavior of a film in aqueous media, a measure of its resistance to water, and thus about the hydrophily of the related material.

The water solubility value of film was established to be
After determining the water sorption isotherm of the obtained film,(fig. 5), resulted a water activity of 0.127 and a value of the monolayer, $m_{0}$ of $0.063 \mathrm{~g}$ water $/ \mathrm{g}$ film.

The values of peroxides index determined for butter samples show the role of antioxidant on lipid oxidation.

Lipid oxidation is one of the mostimportant mechanisms for breaking down food. It is a severe defect that matters in food preservation and it can offer food an off-flavor and odor.

Lipid oxidation is such an important food deterioration, which has caught thousands of food scientists' views and food industries' attention to figure out means to inhibit this reaction. Antioxidants are the most common compound used to preventlipid oxidation.

The peroxide values of butter samples ranged between $0.32 \mathrm{mEq} \mathrm{O}$ to $8.8 \mathrm{mEq} \mathrm{O}_{2} / \mathrm{Kg}$ for samples wraped in paper respectively between $0.32 \mathrm{mEq} \mathrm{O} / \mathrm{Kg}$ butter $-4.0 \mathrm{mEq} \mathrm{O} /$ $\mathrm{Kg}$ butter wraped in polymer film obtained from mixture of starch and polyphenolic extract, (fig. 6).

The results showed that antioxidants had an effect on lipid oxidation, (fig. 7).

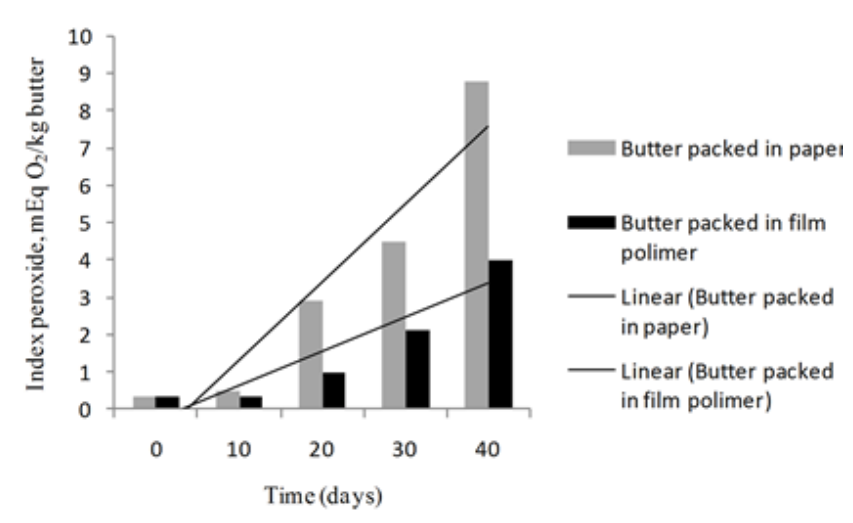

Fig. 6. The values of peroxides indexes for butter

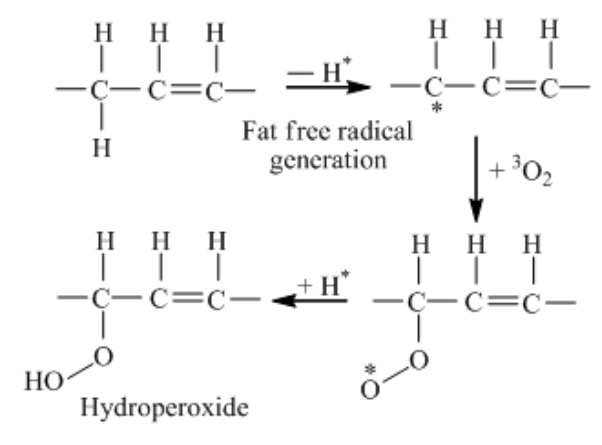

Formation and propagation of free radical

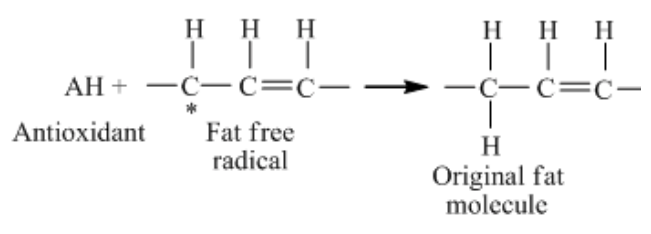

Termination of free radical by antioxidant

Fig. 7.Antioxidant mechanism [43]

\section{Conclusions}

The acorns of Quercus roburL. due to the starch content are an important source of natural biopolymers. The physical and chemical properties of film recommends to use it as wraps in food industry. Starch is compatible with 
antioxidants of Vitis vinifera seeds and for this reason are used to protect chemical compounds in foods.

\section{References}

1.GUILBERT, S., CUQ, B., \& GONTARD, N., Food Addit. Contam., 14, nr. 6, 1997, p. 741.

2.KESTER, J. J., \& FENNEMA, O. R., Food Tech., 48, 1986, p. 47.

3.SILVA-WEISS, A., C., 2012. Development of edible coatings and films based on hydrocolloid blends with polyphenol-rich extract: rheology and functionality, available online at http://dspace2.conicyt.cl/ bitstream/handle/SILVA_ANDREA_2500D.

4.BIFANI, V., RAMIREZ̄, C., IHLL, M., RUBILAR, M., GARCIA, A., ZARITZKY, M., Food Sci. Technol., 40, nr. 8, 2007, p. 1473.

5.GOMEZ-GUILLEN, C., IHL, M., BIFANI, V., SILVA, A., \& MONTERO, P., Food ydrocoll., 21, nr. 7, 2007, p. 1130.

6.FERNANDEZ-PAN, I. AND CABALLERO, J. I. M., Biopolymers for edible films and coating in food appliocations, In Biopolymers: New Materials for Sustainable Films and Coatings, Editor David Plackett John Wiley \& Sons, Roskilde, Denmark, 2011, Cap. XI, p. 74.

7.IMAMA H. S., WOOD, F. D., ABDELWAHAB, M., CHIOU, B., S., WILLIAMS, G. T., GLENN, M. G. AND ORTS, J. W., Starch. Chemistry, Microstructure, Processing and Enzymatic Degradation, In StarchBased Polymeric Materials and Nanocomposites. Edited by lasim Ahmed, Brijesh K. Tiwari, Imam H. Syed, Rao M. A., CRC Press, Taylor \& Francis Group, Danvers, USA, 2012, p. 8.

8.MULLER, C. M. O., BORGES LAURINDO, J., YAMASHITA, F., Food Hydrocoll., 25, nr. 5, 2009, p.1328.

9.BILBAO-SÁINZ, C., AVENA-BUSTILLOS, R.J ., WOOD, D.F., WILLIAMS, T.G., MCHUGH, T.H., J. Agr. Food Chem., 58, nr. 6, 2010, p. 3753.

10. CHIUMARELLI, M., HUBINGER, M., Food Hydrocoll., 28, nr. 1, 2012, p. 59.

11.SUPUT, Z D., VERA L. L., SENKA, Z. P., NEVENA, M. H., Food and Feed Res., 42, nr. 1, 2015, p. 11.

12.HYTTEBORN, H., ASLOV, A. A., NAZIMOVA, D.I. AND RYSIN, L. P., Boreal forests of Eurasia, In First edition Coniferous forests, Edit. Elsevier B.V., Amsterdam, 2005, p. 23-100.

13.RABABAH, T., EREIFEJ, K., AL-MAHASNEH. M., ALHAMAD. M., ALRABABAH, M., AND AL-U'DATT, M., Jordan J. Agric. Sci. 4, 2008, p. 131.

14.AL-ROUSAN, W.M., AJ O, R. Y., AL-ISMAIL, K. M., ATTLEE, A., SHAKER, R. R., OSAILI, T. M., Grasas y Aceites, 64, nr. 5, 2013, p. 554.

15.POP, F., BOLTEA, D., J. Agroalimen. Proc. Technol., 20, nr. 1, 2014, p. 39.

16.BITA, M. G. (DUMITRU), PREDA, M., Riv. Ital. Sostanze Gr., LXXXI, nr. 5, 2004a, p. 326.

17.DUMITRU, M. G., GANESCU, A., DABULEANU, I., Mat. Plast., 53, no. 3, 2016, p. 414.

18.BITA, M. G., (DUMITRU), GHIVERCEA, V., CHILOM, P., J. Environ. Prot. Ecol., 13, nr. 2A, 2012, p. 890.
19.DUMITRU, M. G., VASILE, N. I., BACIU, A. A., Rev. Chim.(Bucharest), 66, no. 1, 2015, p. 97.

20.J AVIERA, F. R., RUI, M. S. C., HELDER, D. S., ANTONIO, A. V., IGOR, K., MARGARIDA, C. V., J. Food Eng., 115, 2013, p. 466.

21.OLAJ IRE, A. A and AZEEZ, L., Afr. J. Food Sci., 2, nr. 2, 2011. p. 022. 22.HARA, S., TOTANI, Y., J. Am. Oil Chem. Soc., 65, nr.12, 1988, p.1948. 23.BITA (DUMITRU), M. G., PREDA, M., Riv. Ital. Sostanze Gr., 80, nr.6, 2004b, p. 377.

24.BITA (DUMITRU), M. G., PREDA, M., Rev. Chim.(Bucharest), 56, no. 7, 2005, p.716.

25.ROONEY, M.L., Active food packaging, In: Rooney ML (ed) Blackie Academic \& Professional, Glasgow, 1995, p 1-37.

26.BRODY, A. L., STRUPINSKY, E. P., KLINE, L. R., Active Packaging for Food Applications, CRC Press, New York 2001, p. 11-30, 131-194.

27.THARANATHAN, R., Trends Food Sci. Technol., 14, 2003, p. 71.

28.MOKREJ S, P., JANACOVA, J., SVOBODA, P., AND CERMAK, R., Res. J. Pharm. Biol. Chem. Sci., 3, nr. 3, 2012, p. 465.

29.SELIGRA, P. G., MEDINA, J., FAMÁ, L., GOYANES, S., Carbohydr. Polym., 138, 2016, p. 66.

30.BERCHEI, O., Raspandirea in Romania a plantelor anemofile cu potential allergenic. 2016, available online at http://www.viatamedicala.ro/*articlelD 5124-dArt.html.

31.PERAZZO, K. K., CONCEICAO, A. C. DOS SANTOS, J. C., ASSIS, DDE J., SOUZA, C. O., DRUZIAN, J. I., PLoS one, 9, e105199, 2014.

32.MORADI, M., TAJIK, H., ROHANI, S.M.R., OROMIEHIE, A.R., MALEKINEJAD, H., ALIAKBARLU, J., HADIAN, M., Food Sci. Technol., 46, 2012, p. 477.

33.VIEIRA, M. G. A., DA SILVA, M. A., SANTOS, L. O., BEPPU, M. M., Eur. Polym J., 47, 2011, p. 254.

34.GIMENEZ, B., LACEY, A. L., PEìREZ-SANTIN, E. ,LOPEZ-CABALLERO, M. E., MONTERO, P., Food Hydrocoll., 30, 2013, p. 264.

35.VERMEIREN, L., DEVLIEGHERE, F., VAN BEEST, M., DE KRUIJF, N., DEBEVERE, J., Trends Food Sci. Technol. 10, 1999, p. 77.

36.SOUZA, C. O., SILVA, L. T., SILVA, J. R, LOPEZ, J. A., VEIGA-SANTOS, P., J. Agric. Food Chem., 59, 2011, p. 2248.

37.FALGUERA, V., QUINTERA, J. P., JIMENEZ, A., MUNOZ, J. A., IBARZ, A., Trends. Food Sci. Technol., 22, 2011, p. 292.

38.MILLER, K. S., KROCHTA, J. M., Trends Food Sci. Tech., 8, 1997, p. 228.

39.NERlìn, C., TOVAR, L., SALAFRANCA, J., J. Food Eng., 84, 2008, p. 313.

40.WESSLING, C., NIELSEN, T., ANDRES, L., Packag. Technol. Sci. 13, 2000, p. 19.

41.SHI, J., YU, J., POHORLY, Y. K., J. Med. Food, 6, nr. 4, 2007, p. 291. 42.BITA (DUMITRU), M. G., PREDA, M., Rev. Chim. Bucharest), 58, no. 6, 2007, p. 494

43.DIPAK, P., Trends in Post Harvest Technology, 1, nr. 1, 2013, p. 68.

Manuscript received: 6.12 .2016 